University of Nebraska - Lincoln

DigitalCommons@University of Nebraska - Lincoln

Publications from USDA-ARS / UNL Faculty

U.S. Department of Agriculture: Agricultural

Research Service, Lincoln, Nebraska

2012

\title{
Evaluating the two-source energy balance model using local thermal and surface flux observations in a strongly advective irrigated agricultural area
}

\author{
William P. Kustas \\ USDA-ARS, Bill.Kustas@ars.usda.gov \\ Joseph G. Alfieri \\ USDA-ARS, joe.alfieri@ars.usda.gov \\ Martha C. Anderson \\ USDA-ARS, martha.anderson@ars.usda.gov \\ Paul D. Colaizzi \\ USDA-ARS, Paul.Colaizzi@ARS.USDA.GOV \\ John H. Prueger \\ USDA-ARS, john.prueger@ars.usda.gov \\ See next page for additional authors \\ Follow this and additional works at: https://digitalcommons.unl.edu/usdaarsfacpub
}

Kustas, William P.; Alfieri, Joseph G.; Anderson, Martha C.; Colaizzi, Paul D.; Prueger, John H.; Evett, Steven R.; Neale, Christopher M. U.; French, Andrew N.; Hipps, Lawrence E.; Chávez, José L.; Copeland, Karen S.; and Howell, Terry A., "Evaluating the two-source energy balance model using local thermal and surface flux observations in a strongly advective irrigated agricultural area" (2012). Publications from USDA-ARS / UNL Faculty. 1839.

https://digitalcommons.unl.edu/usdaarsfacpub/1839

This Article is brought to you for free and open access by the U.S. Department of Agriculture: Agricultural Research Service, Lincoln, Nebraska at DigitalCommons@University of Nebraska - Lincoln. It has been accepted for inclusion in Publications from USDA-ARS / UNL Faculty by an authorized administrator of DigitalCommons@University of Nebraska - Lincoln. 


\section{Authors}

William P. Kustas, Joseph G. Alfieri, Martha C. Anderson, Paul D. Colaizzi, John H. Prueger, Steven R. Evett, Christopher M. U. Neale, Andrew N. French, Lawrence E. Hipps, José L. Chávez, Karen S. Copeland, and Terry A. Howell 


\title{
Evaluating the two-source energy balance model using local thermal and surface flux observations in a strongly advective irrigated agricultural area
}

\author{
Karen S. Copeland $^{\mathrm{b}}$, Terry A. Howell ${ }^{\mathrm{b}}$ \\ ${ }^{a}$ USDA-Agricultural Research Service, Hydrology \& Remote Sensing Lab, Bldg 007, BARC-West, Beltsville, MD 20705, USA \\ ${ }^{\mathrm{b}}$ USDA-ARS Conservation and Production Research Lab, P.O. Drawer 10, Bushland, TX 79012, USA \\ ' USDA-ARS National Lab of Agriculture and the Environment, 2110 Univ. Blvd. Ames, IA 50011, USA \\ ${ }^{\mathrm{d}}$ Bio E Irrigation Engr., Utah State Univ., 4105 Old Main Hill, Logan, UT 84322-4105, USA \\ ${ }^{\mathrm{e}}$ USDA-ARS Arid-Land Agricultural Research Center, 21881 North Cardon Lane, Maricopa, AZ 85238, USA \\ ${ }^{\mathrm{f}}$ Plants, Soils E Climate Depart., Utah State Univ., 4105 Old Main Hill, Logan, UT 84322-4105, USA \\ ${ }^{\mathrm{g}}$ Dept. of Civil \&' Environ. Engr., Colorado State Univ., 1372 Campus Deliv., Fort Collins, CO 80523, USA
}

William P. Kustas a,*, Joseph G. Alfieri ${ }^{a}$, Martha C. Anderson ${ }^{\text {a }}$, Paul D. Colaizzi ${ }^{\mathrm{b}}$, John H. Prueger ${ }^{\mathrm{c}}$, Steven R. Evett ${ }^{\mathrm{b}}$, Christopher M.U. Neale ${ }^{\mathrm{d}}$, Andrew N. French ${ }^{\mathrm{e}}$, Lawrence E. Hipps ${ }^{\mathrm{f}}$, José L. Chávez ${ }^{\mathrm{g}}$,

\section{A R T I C L E I N F O}

\section{Article history}

Available online 20 July 2012

\section{Keywords:}

Thermal remote sensing

Two-source energy balance modeling

Land surface temperature

Evapotranspiration

Time differencing methods

\begin{abstract}
A B S T R A C T
Application and validation of many thermal remote sensing-based energy balance models involve the use of local meteorological inputs of incoming solar radiation, wind speed and air temperature as well as accurate land surface temperature (LST), vegetation cover and surface flux measurements. For operational applications at large scales, such local information is not routinely available. In addition, the uncertainty in LST estimates can be several degrees due to sensor calibration issues, atmospheric effects and spatial variations in surface emissivity. Time differencing techniques using multi-temporal thermal remote sensing observations have been developed to reduce errors associated with deriving the surface-air temperature gradient, particularly in complex landscapes. The Dual-Temperature-Difference (DTD) method addresses these issues by utilizing the Two-Source Energy Balance (TSEB) model of Norman et al. (1995) [1], and is a relatively simple scheme requiring meteorological input from standard synoptic weather station networks or mesoscale modeling. A comparison of the TSEB and DTD schemes is performed using LST and flux observations from eddy covariance (EC) flux towers and large weighing lysimeters (LYs) in irrigated cotton fields collected during BEAREX08, a large-scale field experiment conducted in the semi-arid climate of the Texas High Plains as described by Evett et al. (2012) [2]. Model output of the energy fluxes (i.e., net radiation, soil heat flux, sensible and latent heat flux) generated with DTD and TSEB using local and remote meteorological observations are compared with EC and LY observations. The DTD method is found to be significantly more robust in flux estimation compared to the TSEB using the remote meteorological observations. However, discrepancies between model and measured fluxes are also found to be significantly affected by the local inputs of LST and vegetation cover and the representativeness of the remote sensing observations with the local flux measurement footprint.
\end{abstract}

Published by Elsevier Ltd.

\section{Introduction}

The energy balance at the land surface, and in particular the partitioning of the available energy $\left(R_{N}-G\right)$ into sensible $(H)$ and latent heat flux $(L E)$, significantly affects important hydrologic and atmospheric processes and is a key indicator of the surface moisture status. For irrigated agriculture, the latent heat flux (or evapotranspiration (ET) when expressed as rate of water loss) is

\footnotetext{
* Corresponding author. Address: USDA, ARS, Hydrology and Remote Sensing Laboratory, Bldg 007, Rm 104, BARC-W, 10300 Baltimore Ave, Beltsville, MD 20705 , USA. Tel.: +1 3015048498 .
}

E-mail address: Bill.Kustas@ars.usda.gov (W.P. Kustas). tied to crop water requirements, irrigation applications, and vegetation stress. Land surface temperature (LST) is a fundamental surface state variable that is strongly coupled to the surface energy balance and ET [3]. For this reason, studies have evaluated the utility of LST as a key boundary condition and metric for modeling water use and availability, which is tied to plant growth and carbon assimilation (e.g., [4]). Consequently, LST provides a means for monitoring crop water use, stress and ultimately yield (e.g., [5,6]). Kalma et al. [7] review land surface schemes of varying degrees of complexity that involve the use of LST for estimating the surface energy balance and the relative partitioning of the available energy $\left(R_{N}-G\right)$ at the land surface between $\mathrm{H}$ and LE. 
While LST is a useful controlling variable in energy balance modeling, uncertainties in accounting for variations in thermal emissivity, atmospheric corrections, radiometer viewing angle, and sensor calibration can significantly degrade the accuracy of LST retrievals from remotely sensed brightness temperatures [8]. Another complicating factor is the need for specifying surface layer atmospheric properties (principally wind speed and air temperature) over the modeled landscape. Errors in LST and meteorological boundary conditions can render many approaches that rely on surface-air temperature differences to be rather tenuous when applied to heterogeneous landscape conditions [9].

Anderson et al. [10] describes remote sensing techniques that have been developed which attempt to minimize the impacts of many of the uncertainties in LST and meteorological forcing variables. One approach uses maximum and minimum LST from remotely sensed temperatures along with energy balance constraints to define model variables. Another methodology uses time-differencing techniques to reduce the sensitivity to the requirement of an absolute LST-air temperature difference. A simplified form of a temperature-differencing approach, called the Dual-Temperature-Difference (DTD) scheme, was developed for routine applications using continuous ground-based or geostationary satellite observations of LST $[11,12]$. The land-surface scheme in the DTD is based on the Two-Source Energy Balance (TSEB) model framework of Norman et al. [1], which accounts for the main physical factors causing differences between aerodynamic temperature and radiometric LST [13].

For irrigated croplands in strongly advective environments, there are likely to be significant variations in near surface/screen level ( $\sim 2 \mathrm{~m}$ ) atmospheric properties used as upper boundary conditions in model implementations. As a result, direct applications of a land-surface model like TSEB at large scales are questionable in the absence of a relatively dense network of weather station observations. The DTD, however, is less sensitive to errors in air temperature boundary conditions, and may be more accurate for regional applications. In this study, the relative utility of the TSEB and DTD formulations were evaluated using local LST observations from several locations within an irrigated cotton field collected during the 2008 Bushland Evapotranspiration and Agricultural Remote sensing EXperiment (BEAREX-08) at the USDA-ARS Conservation and Production Research Laboratory at Bushland, Texas. Both local meteorological observations collected within the field site and remote observations obtained from the regional airport in Amarillo, TX approximately $35 \mathrm{~km}$ from the BEAREX08 study site were used in the TSEB and DTD model computations to assess sensitivity to input errors. Model surface flux output, using both local and remote inputs, is compared to eddy covariance and lysimeter measurements collected during BEAREX08.

This study also looks in detail at the importance of using LST and vegetation inputs that are spatially consistent with the surface footprint sampled by the flux instrumentation used for model evaluation. Proper selection of model inputs in relationship to the validation dataset is essential for isolating model errors from input errors over strongly heterogeneous landscapes. An example is provided for a case where model-measurement differences are exacerbated due to a mismatch in remotely-sensed surface boundary conditions and source area contributing to the flux measurement for a strongly advective environment.

\section{Model overview}

\subsection{Two-source energy balance (TSEB) model formulation}

The TSEB scheme originally proposed by Norman et al. [1] has gone through several revisions, improving the representation of shortwave and longwave radiation exchange within the soil-canopy system as well as soil-canopy interactions [14,15-17]. In TSEB, the satellite-derived directional radiometric surface radiometric temperature at viewing angle $\phi, T_{R}(\phi)$, is considered to be a composite of the soil surface and canopy temperatures, expressed as:

$T_{R}(\phi) \approx\left[f_{C}(\phi) T_{C}^{4}+\left(1-f_{C}(\phi)\right) T_{S}^{4}\right]^{1 / 4}$

where $T_{C}$ is canopy temperature, $T_{S}$ is soil surface temperature, and $f_{c}(\phi)$ is the fractional vegetation cover observed at the radiometer view angle $\phi$. For a canopy with a spherical leaf angle distribution and leaf area index $L A I, f_{C}(\phi)$ can be expressed as

$f_{C}(\phi)=1-\exp \left(\frac{-0.5 \Omega L A I}{\cos \phi}\right)$

where the factor $\Omega$ indicates the degree to which vegetation is clumped, as in row crops or sparse shrubland canopies [14,17]. Recent modifications for computing $\Omega$ for row crops suggested by Anderson et al. [18] and Colaizzi et al. [19] were used in this study and yielded $\Omega$ values ranging from 0.5 to 0.9 as the canopy fractional cover and LAI varied over the study period. The $T_{C}$ and $T_{S}$ are used to compute the surface energy balance for the canopy and soil components of the composite land-surface system:

$R_{N S}=H_{S}+L E_{S}+G$

$R_{N C}=H_{C}+L E_{C}$

where $R_{N S}$ is net radiation at the soil surface and $R_{N C}$ is net radiation divergence in the vegetated canopy layer, $H_{C}$ and $H_{S}$ are the canopy and soil sensible heat fluxes, respectively, $L E_{C}$ is the canopy transpiration rate, $L E_{S}$ is soil evaporation, and $G$ is the soil heat flux.

By permitting the soil and vegetated canopy fluxes to interact with each other, Norman et al. [1] derived expressions for $H_{C}$ and $H_{S}$ as a function of temperature differences, with:

$H_{C}=\rho C_{P} \frac{T_{C}-T_{A C}}{R_{X}}$

and

$H_{S}=\rho C_{P} \frac{T_{S}-T_{A C}}{R_{S}}$

so that the total sensible heat flux, $H=H_{C}+H_{S}$, is equal to

$H=\rho C_{P} \frac{T_{A C}-T_{A}}{R_{A}}$

where $\rho$ is the density of air $\left(\mathrm{kg} \mathrm{m}^{-3}\right), C_{P}$ is the specific heat of air $\left(\sim 1000 \mathrm{~J} \mathrm{~kg}^{-1} \mathrm{~K}^{-1}\right), T_{A C}$ is an air temperature in the canopy air layer $\left({ }^{\circ} \mathrm{C}\right)$ closely related to the aerodynamic temperature, $R_{X}$ is the total boundary layer resistance $\left(\mathrm{s} \mathrm{m}^{-1}\right)$ of the complete canopy of leaves, $R_{S}$ is the resistance $\left(\mathrm{s} \mathrm{m}^{-1}\right.$ ) to sensible heat exchange from the soil surface, and $R_{A}$ is aerodynamic resistance $\left(\mathrm{s} \mathrm{m}^{-1}\right)$. Resistance terms are defined in Norman et al. [1] with recent revisions described in Kustas and Norman [14-17]. Weighting of the heat flux contributions from the canopy and soil components is performed indirectly by the partitioning of the net radiation between soil and canopy and via the impact on resistance terms by the fractional amount and type of canopy cover [see 15]. The resistances $R_{X}$ and $R_{S}$ effectively account for the excess resistance parameterizations in one-source energy balance (OSEB) modeling approaches where this additional resistance is introduced typically ad-hoc in OSEB formulations to account for the less efficient transport of heat relative to momentum transport near the surface elements [3]. With resistance formulations for heat transfer from the soil and canopy elements, this results in a more realistic representation of the soil and vegetation influence on the rate of (or resistance to) turbulent heat exchange with the overlying atmosphere and a physically-based means of relating soil and canopy temperatures to the radiometric surface 
temperature [1]. As a result, the TSEB model is shown to be significantly more robust than OSEB approaches over a wide range of environmental and land cover conditions [3].

For the latent heat flux from the canopy, a modified form of the Priestley-Taylor equation for equilibrium ET [20] is used to initially estimate $L E_{C}$

$L E_{C}=\alpha_{P T C} f_{G} \frac{\Delta}{\Delta+\gamma} R_{N C}$

Here, $\alpha_{\text {PTC }}$ is a variable related to the so-called Priestley-Taylor coefficient, but in this case defined exclusively for the canopy component, as was suggested for row crops by Tanner and Jury [21]. The variable $\alpha_{\text {PTC }}$ is normally set to an initial value of $\sim 1.3$, except under well watered partial canopy cover conditions in strongly advective environments where a higher value $\left(\alpha_{\text {PTC }} \sim 2\right)$ may be more appropriate [14,22], $f_{G}$ is the fraction of green vegetation, $\Delta$ is the slope of the saturation vapor pressure versus temperature curve $\left(\mathrm{kPa} \mathrm{C}^{-1}\right)$, and $\gamma$ is the psychrometric constant $(\sim 0.06 \mathrm{kPa}$ $\mathrm{C}^{-1}$ ). Although this study had strong advection, the vapor pressure deficits were not extremely large and therefore $\alpha_{\text {PTC }}$ was assigned a value of 1.3 [23]. Under stress conditions, the TSEB model iteratively reduces $\alpha_{\text {PTC }}$ from its initial value, as described below.

The latent heat flux from the soil surface is solved as a residual to the energy balance equation

$L E_{S}=R_{N S}-G-H_{S}$

with $G$ estimated as a fraction of the net radiation at the soil surface (both in $\mathrm{W} \mathrm{m}^{-2}$ ):

$G=c_{G} R_{N S}$.

The value of $c_{G}$ varies with soil type and moisture conditions as well as time of day, due to the phase shift between $G$ and $R_{N S}$ over a diurnal cycle [24]. Although for the midmorning to midday period, when TIR satellite imagery are typically acquired, the value of $c_{G}$ can be assumed constant [24,25], but in this study the adjustment to $c_{G}$ suggested by Santanello and Friedl [24] was applied since the model is run over most of the daytime period (i.e., $R_{\mathrm{N}}>100$ $\mathrm{W} \mathrm{m}^{-2}$ ). This formulation produced a variable $\mathrm{c}_{\mathrm{G}}$ ranging from 0.15 to 0.35 which better matched the observations.

The TSEB formulation requires a solution to both the radiative temperature balance (Eq. (1)) and the energy balance (Eqs. (3) and (4)), with physically plausible model solutions for soil and vegetation temperatures and fluxes. Unrealistic solutions, such as daytime condensation at the soil surface (i.e., $L E_{s}<0$ ), can be obtained under conditions of moisture deficiency. This happens because $L E_{C}$ is overestimated in these cases by the Priestley-Taylor parameterization, which assumes potential transpiration. The higher $L E_{C}$ leads to a cooler $T_{C}$ and $T_{S}$ must be accordingly larger to satisfy Eq. (1), and this larger $T_{S}$ drives $H_{S}$ too high, forcing the residual $L E_{S}$ from Eq. (9) to become negative. If this condition is encountered by the TSEB scheme, $\alpha_{\text {PTC }}$ is iteratively reduced until $L E_{S} \sim$ 0 (expected for a dry soil surface). A more thorough discussion of conditions that force a reduction in $\alpha_{\text {PTC, }}$ is given by Anderson et al. [18] and Li et al. [26].

\subsection{Dual-temperature-difference (DTD) formulation}

Details of the derivation of the DTD model are described in Norman et al. [11]. Briefly, the two-source-time-integrated equations of Anderson et al. [27], currently called the Atmosphere-Land-Exchange-Inverse (ALEXI) model using the TSEB formulations of Norman et al. [1], are used to form a double difference of radiometric and air temperatures so that an estimate of sensible heat flux can be obtained from measurements of surface radiometric temperature, air temperature, and wind speed, and estimates of vegetation height, fractional cover, type and approximate leaf size. The expression used is the following:

$T_{R, i}(\phi)-T_{A, i}=f_{C}(\phi) \frac{H_{C, i} R_{A, i}}{\rho C_{p}}+\left(1-f_{C}(\phi)\right) \frac{\left(H_{i}-H_{C, i}\right)\left(R_{A, i}+R_{S, i}\right)}{\rho C_{p}}$

where the $i$ subscript refers to time, $H_{C, i}$ is the sensible heat flux from the vegetative canopy at time $i, H_{i}$ is the total sensible heat flux above the canopy arising from both vegetation and soil components, and the resistances at time $i$, namely $R_{A, i}$ and $R_{S, i}$ are defined above in the TSEB formulation.

The sensible heat from the canopy, $H_{C, i}$, is estimated from the net radiation divergence of the vegetative canopy $\left(R_{N C, i}\right)$ using the modified Priestley-Taylor expression (Eq. (8)) and solving for energy balance of the canopy (Eq. (4))

$H_{C, i}=R_{N C, i}\left[1-\alpha_{P T C} f_{g} \frac{\Delta}{\Delta+\gamma}\right]$

The net radiation divergence equation used in the DTD formulation in Norman et al. [11] assumes an exponential decay of bulk $R_{N}$ through the canopy layer, which is simpler than the TSEB radiation formulations that separately consider both shortwave and longwave transfer through the canopy elements. The most recent equations for estimating the aerodynamic resistances above the canopy and above the soil surface are referenced in Norman et al. [11].

The two terms on the right hand side of Eq. (11) represent the contributions of the vegetation and soil components to the sensible heat flux assuming the flux exchange between the atmosphere and vegetation and soil components are in parallel, which is a simpler version of the TSEB derived originally by Norman et al. [1]. In the DTD method, Eq. (11) is applied at two times. The first time usually is chosen when all the fluxes are small and the surface and air temperatures are similar; this typically occurs approximately one hour after sunrise, so $i=0$ at this time. The second time can be any hour during the day. Applying Eq. (11) at two times $(0, i)$ and subtracting the equations yields the following:

$$
\begin{aligned}
H_{i}= & \rho C_{P}\left[\frac{\left(T_{R, i}(\phi)-T_{R, 0}(\phi)\right)-\left(T_{A, i}-T_{A, 0}\right)}{\left(1-f_{C}(\phi)\right)\left(R_{A, i}+R_{S, i}\right)}\right] \\
& +H_{C, i}\left[1-\frac{f_{C}(\phi)}{1-f_{C}(\phi)} \frac{R_{A, i}}{R_{A, i}+R_{S, i}}\right] \\
& +\left(H_{0}-H_{C, 0}\right)\left[\frac{R_{A, 0}+R_{S, 0}}{R_{A, i}+R_{S, i}}\right]+H_{C, 0}\left[\frac{f_{C}(\phi)}{1-f_{C}(\phi)} \frac{R_{A, 0}}{R_{A, i}+R_{S, i}}\right]
\end{aligned}
$$

The last two terms on the right side of Eq. (13) involving $H_{0}$ and $H_{C, 0}$ are often negligible an hour after sunrise [see 11].

Eq. (13) represents a relatively simple result with the advantage that any offset between measurements of $T_{R, i}(\phi)$ and $T_{A, i}$ are canceled in the temperature term. Given estimates of net radiation $\left(R_{N, i}\right)$ and soil heat conduction flux $\left(G_{i}\right)$ at time $i$, the latent heat flux, $L E_{i}$, can be calculated from the surface energy balance equation:

$L E_{i}=R_{N, i}-G_{i}-H_{i}$

\section{Data}

The local meteorological observations, surface energy flux measurements, and remote sensing data used in running the TSEB and DTD models were collected from an irrigated cotton field site located at the USDA-ARS, Conservation and Production Research Laboratory (CPRL), in Bushland, TX $\left(35^{\circ} 11^{\prime} \mathrm{N}, 102^{\circ} 06^{\prime} \mathrm{W}\right)$. The experimental site lies within the Texas High Plains region, at an elevation of approximately $1170 \mathrm{~m}$ above mean sea level. Soils in 


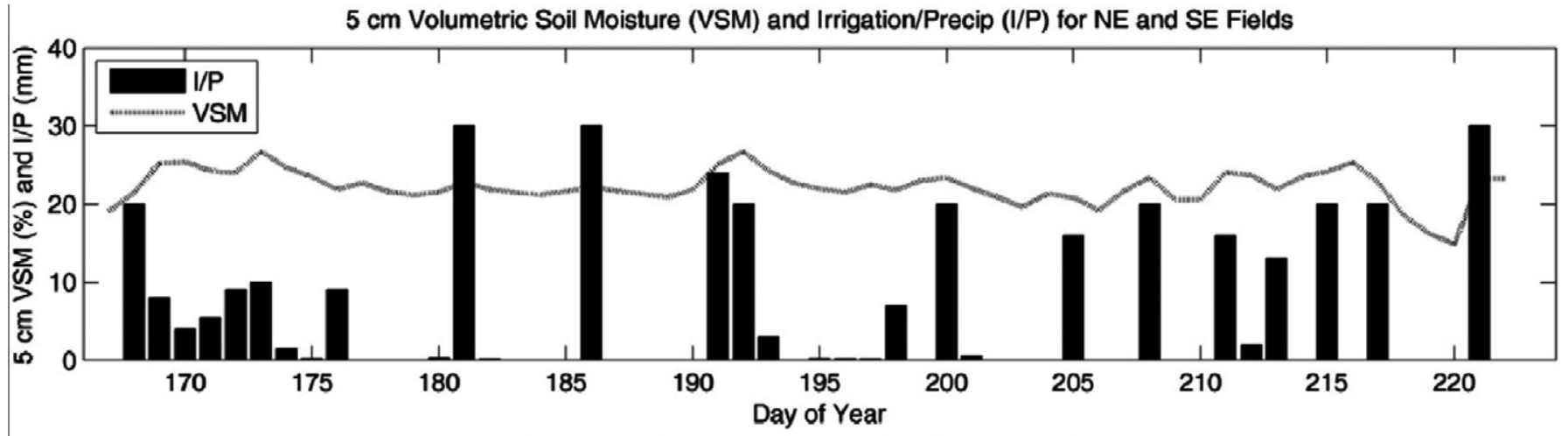

LAI Estimates from EC1 and EC8 and NE LY Locations

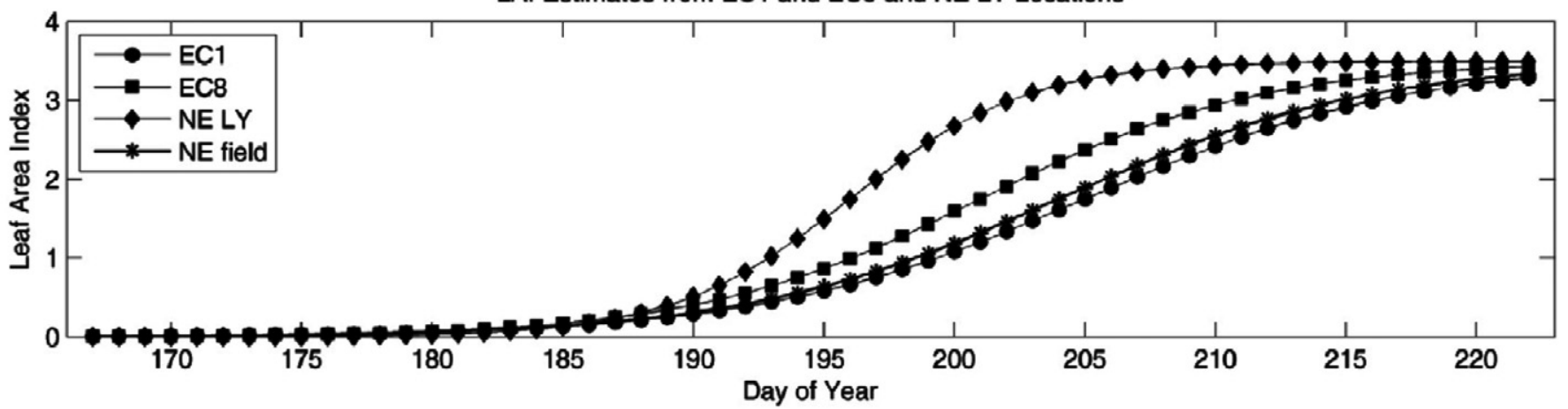

LAI Estimates from EC2 and EC9 and SE LY Locations

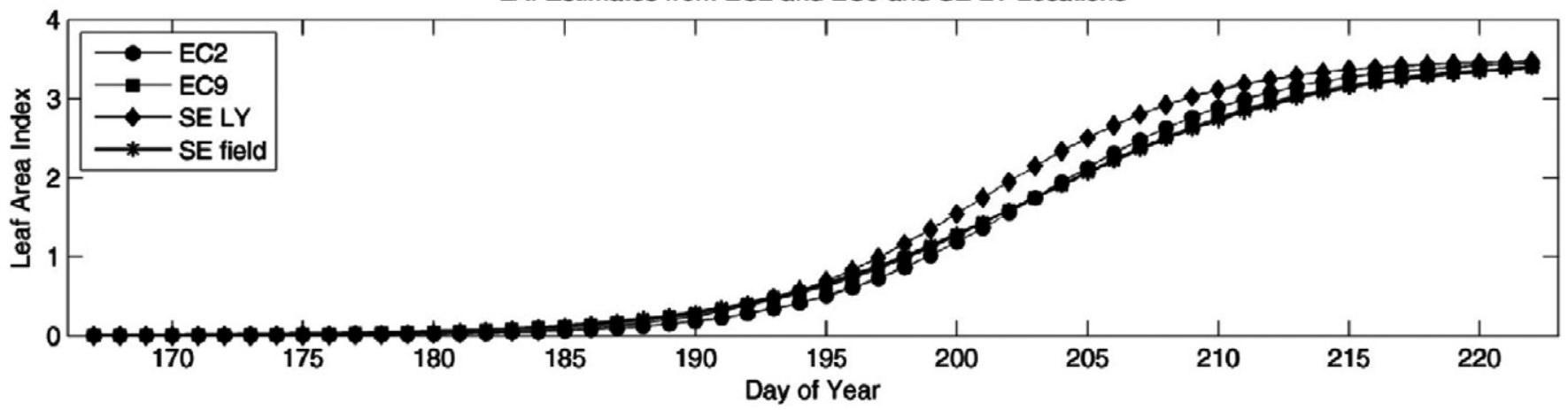

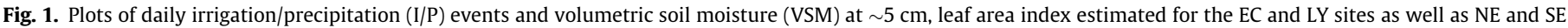
field averages for the 2nd IOP (Day of Year 167 to 222).

and around Bushland are classified as slowly permeable Pullman clay loam. The measurements were collected on experimental cotton fields, approximately 5-ha squares in size. In the center of each field was a large weighing lysimeter (nominally $3 \times 3 \times 2.4-\mathrm{m}$ deep). Details of the monolithic weighing lysimeters are given by Marek et al. [28], and a discussion of the measurements and procedures used to upscale the lysimeter (LY) measurements to reflect average field conditions is given by Evett et al. [29]. Since the LY sites only measure $L E, H$ was computed by residual using locally measured $R_{N}-G$.

Surface energy balance/flux towers using the eddy covariance (EC) technique for measuring the turbulent fluxes ( $H$ and $L E$ ) were located in the four lysimeter fields and in a harvested winter wheat/bare soil site and rangeland/grassland site, both south of the lysimeter fields (see Fig. 2 in [2]). A detailed description of the instrumentation and post processing of the EC/surface energy balance measurements is described in [30]. The local meteorological data of air temperature, wind speed, vapor and atmospheric pressure came from the EC towers at nominally $2 \mathrm{~m}$ above ground level (agl). The remote meteorological data (wind speed at $10 \mathrm{~m}$ and air temperature and vapor pressure at $2 \mathrm{~m}$ ) came from a
NOAA/NWS station located at the Amarillo airport $\left(35.2194^{\circ} \mathrm{N}\right.$, $-101.7059^{\circ} \mathrm{E}$ ), approximately $35 \mathrm{~km}$ away.

Since the objective was to evaluate the utility of the TSEB and DTD techniques under strongly advective conditions, this study used measurements only from the irrigated northeast (NE) and southeast (SE) cotton fields. This allowed for comparisons of model output with measurements from EC towers 1, 8, 2 and 9 and LY measurements for the NE and SE fields (see Fig. 1 in [30]). The EC1 and EC2 towers were located in the northeastern corners of the NE and SE fields, respectively, to maximize fetch for winds, which typically come from the south/southwest. The EC8 and EC9 towers were located in close proximity ( $\sim 20 \mathrm{~m}$ northeast) of the NE and SE LY, respectively, and model tests at these sites used $R_{N}, G$ and LST measurements collected at the LY sites.

LST was measured by two infrared thermometers (IRTs) (Exergen, ${ }^{1}$ 2:1 field of view) over each lysimeter at nominally $2 \mathrm{~m}$ agl, aimed 45 degrees from nadir with approximate southwest

\footnotetext{
1 The mention of trade names of commercial products in this article is solely for the purpose of providing specific information and does not imply recommendation or endorsement by the US Department of Agriculture.
} 
viewing azimuth angles of 45 and 60 degrees from due south. At the EC tower sites, LST was measured using two Apogee (models IRR-PN and IRTS-P, 3:1 field of view) IRTs at nominally $1.25 \mathrm{~m}$ agl, one viewing nadir, the other aimed 45 degrees with due south azimuth angle. For comparison with the IRT data, estimates of LST were also available from longwave pyrgeometers mounted at each site (Kipp \& Zonen CGR3 models at the lysimeter sites, and CNR1 net radiometers at the EC sites, Bohemia, New York), which yields a "hemispherical' surface temperature estimate through inversion of the Stefan-Boltzmann equation [8].

Canopy height and row width measurements and destructive samples of leaf area were collected periodically at key growth stages at sites in the vicinity of the lysimeters. Leaf area at selected sites within each field was also measured with a LI-COR leaf area meter (model LI-3100, Lincoln, Nebraska). A linear interpolation as a function of time based on growing degree days was used by Colaizzi et al. [31] for estimating LAI, plant height and width between vegetation sampling dates. The LAI estimates for the lysimeters and areas surrounding the EC towers were estimated using a sigmoidal relationship between the ground-based LAI samples and remotely sensed vegetation index imagery from aircraft [30]. An interpolation algorithm providing daily LAI estimates was based on an exponential relationship with day of year [30].

The data used for evaluating DTD and TSEB models covered the $2^{\text {nd }}$ intensive observation period (IOP) from approximately day of year (DOY) 167 (June 15) to 222 (August 9). Over this time period, particularly from DOY 190 to 210 , there was a dramatic change in vegetation density (leaf area). Frequent irrigations maintained adequate soil moisture to sustain crop development under high evaporative demand conditions. In Fig. 1, are plots showing dates and quantity of precipitation and irrigations, as well as estimates of
LAI and a representative daytime water content (volumetric soil moisture, VSM) at $\sim 5 \mathrm{~cm}$ from a network of Hydra Probe (Hydra Probe II, Stevens Water Monitoring Systems, Inc., Portland, Oregon) measurements described by Cosh et al. [33]. Note the variability in LAI between locations, particularly in the NE field. The impact of this variation in LAI on model-measurement comparisons is discussed below. A detailed analysis of the impact of variability in vegetation cover on measured fluxes is presented by Alfieri et al. [30].

\section{Results and Discussion}

\subsection{IRT vs. Pyrgeometer estimates of LST}

To assess the relative utility of IRT and pyrgeometer measurements of LST in driving the TSEB and DTD models, temperatures derived from each instrumentation type are compared with measurements at adjacent sites within the same field in Fig. 2. The pyrgeometer observations exhibited less variability between adjacent sites than did the IRT observations, suggesting greater uncertainty in the IRT data due to sampling and instrument stability/accuracy issues. In comparison, the pyrgeometer data appear to yield a more reliable area-averaged/aggregated LST, given that the cotton row crop was clumped and variable in fractional ground cover. Therefore, the pyrgeometer-derived LST data have been used in all the model computations and comparisons with measured fluxes as described below, assuming a nominal view angle of 45 degrees.

\subsection{Energy balance closure for EC flux measurements}

Alfieri et al. [30] noted that the EC flux measurements of $H$ and $L E$ had incomplete energy balance closure with respect to
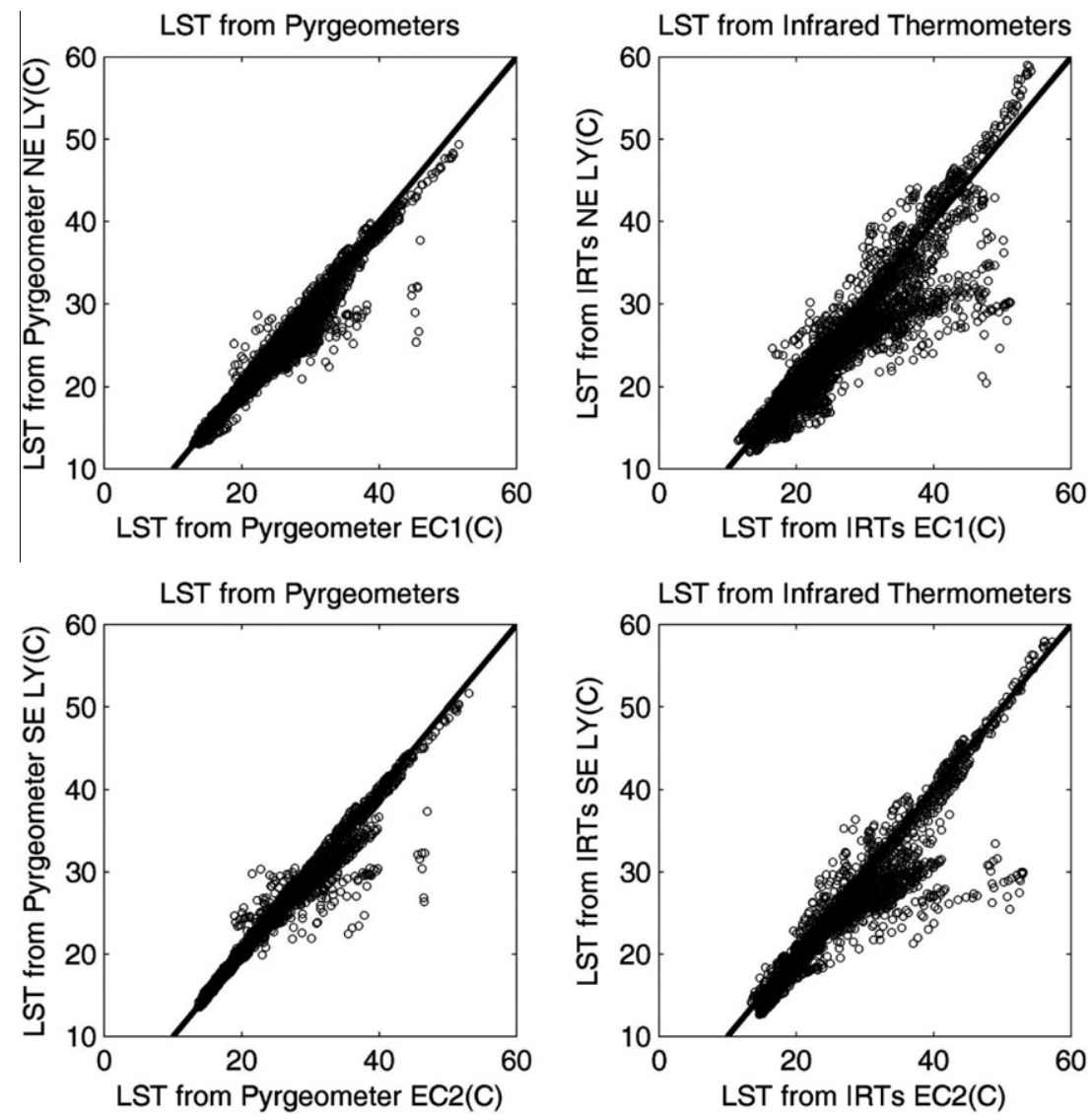

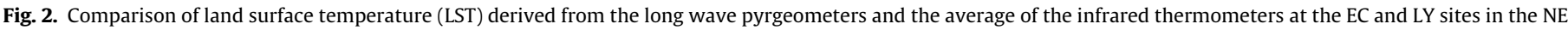
and SE fields. Line represents perfect agreement (1:1). 
the available energy, $R_{N}-G$, with $(H+L E) /\left(R_{N}-G\right)$ ranging from $74 \%$ for EC2 to $87 \%$ for EC8, $84 \%$ for EC1, and $85 \%$ for EC9. Since energy balance models conserve energy by definition, typically energy balance closure is forced among EC flux observations used for model validation. Alfieri et al. [30] forced closure by conserving the Bowen ratio $(H / L E)$ and by residual $\left(L E=R_{N}-G-H\right)$. Under conditions of large $L E$ (small or negative Bowen ratios due strong advection), there are studies suggesting that computing $L E$ as a residual may be a better method for energy balance closure [32]; hence, the residual closure technique was applied in this study. This assumes, of course, that both $R_{N}$ and $G$ measurements are reliable and are representative of the source area/flux footprint affecting the EC measurements.

\subsection{TSEB and DTD model performance using local meteorological inputs}

Model performance was assessed using the mean-absolute-difference (MAD) between measured and modeled fluxes, a statistic recommended by Willmott and Matsurura [34]. In addition the mean-bias-difference (MBD; average of modeled output -measured flux) and mean-absolute-percent-difference (MAPD = MAD/ average measured flux $* 100)$ statistics were also computed. The models were applied to 15-min averaged inputs of solar radiation, air temperature, wind speed, vapor pressure and LST, and the resulting 15-min fluxes were averaged to hourly values for comparison with the hourly averaged EC and LY measurements.

Model results using local meteorological inputs from the NE field are shown in Fig. 3, which illustrates the scatter between hourly flux measurements from the two sites where LST was measured, namely from the EC1 flux tower and NE LY, and the fluxes computed from the DTD and TSEB models. The agreement between measured and modeled fluxes using both modeling approaches is quite similar, although it appears that the TSEB model has a slightly greater bias in $G$ and $H$ at both sites. The scatter is greater in $H$ and $L E$ for the NE LY site, but with a relatively small MBD in $L E$. The comparison between modeled versus measured fluxes for the SE field sites with LST observations, EC2 and SE LY (Fig. 4), indicates less overall bias in $H$ and $L E$ compared with the NE field and better agreement (i.e., smaller MBD values). The statistical results listed in Table 1 confirm what is illustrated in Figs. 3 and 4 . For $R_{N}$, the MAD values among the flux sites are similar for the two models (average MAD, $<M A D>\sim 25 \mathrm{~W} \mathrm{~m}^{-2}$ ) while MBD values are more variable. For $G$, MAD values from the TSEB model are greater than $\mathrm{DTD}$, namely $\left\langle\mathrm{MAD}>\sim 45\right.$ versus $30 \mathrm{~W} \mathrm{~m}^{-2}$, respectively, in large part due to a greater $\langle\mathrm{MBD}>$ of nearly 25 compared with $10 \mathrm{~W} \mathrm{~m}^{-2}$ for TSEB and DTD, respectively. This result is due in part to differences in radiation partitioning algorithm for soil and canopy described in the model overview section. For $H$ and $L E$ the MAD and MBD values for the two models are similar, but with MAD in $L E$ lower for the DTD model by $\sim 5 \mathrm{~W} \mathrm{~m}^{-2}$ on average. This is mainly a result of the fact that by using a time-differencing technique, effects of biases in LST from errors in assumed emissivity or instrument calibration are minimized. For the TSEB and DTD models $\left\langle\mathrm{MAD}>\sim 50 \mathrm{~W} \mathrm{~m}^{-2}\right.$ for $H$ and 65 and $60 \mathrm{~W} \mathrm{~m}^{-2}$ for $L E$, respectively. Values of $\langle\mathrm{MBD}\rangle$ for TSEB and DTD are relatively small at $\sim-25 \mathrm{~W} \mathrm{~m}^{-2}$ and $-15 \mathrm{~W} \mathrm{~m}^{-2}$ for $H$ and $\sim 1$ and $10 \mathrm{~W} \mathrm{~m}^{-2}$ for $L E$, respectively.

\subsection{TSEB and DTD model performance using remote meteorological inputs}

Table 1 also lists the MAD and MBD values obtained in applying the TSEB and DTD models to the remote meteorological (met) data (i.e., from the Amarillo airport). Note that the effect of using the remote met data had a minor impact on $R_{N}$ and $G$ estimates. In almost all cases, the performance of the DTD was similar using local and remote inputs. In contrast, for many sites there was an
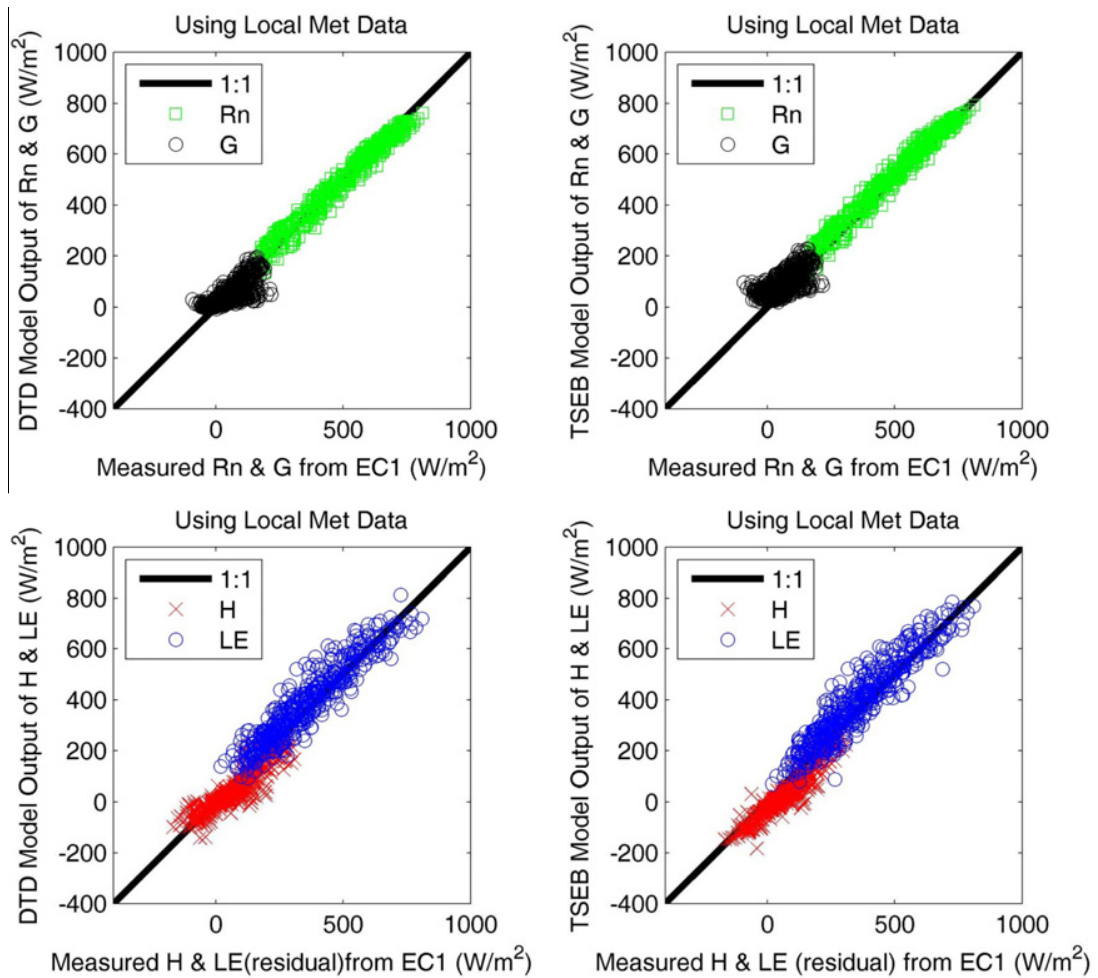

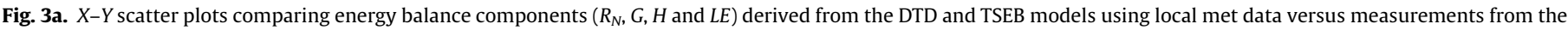
EC1 system deployed in the NE field where LST was measured. The 1:1 line represents perfect agreement 

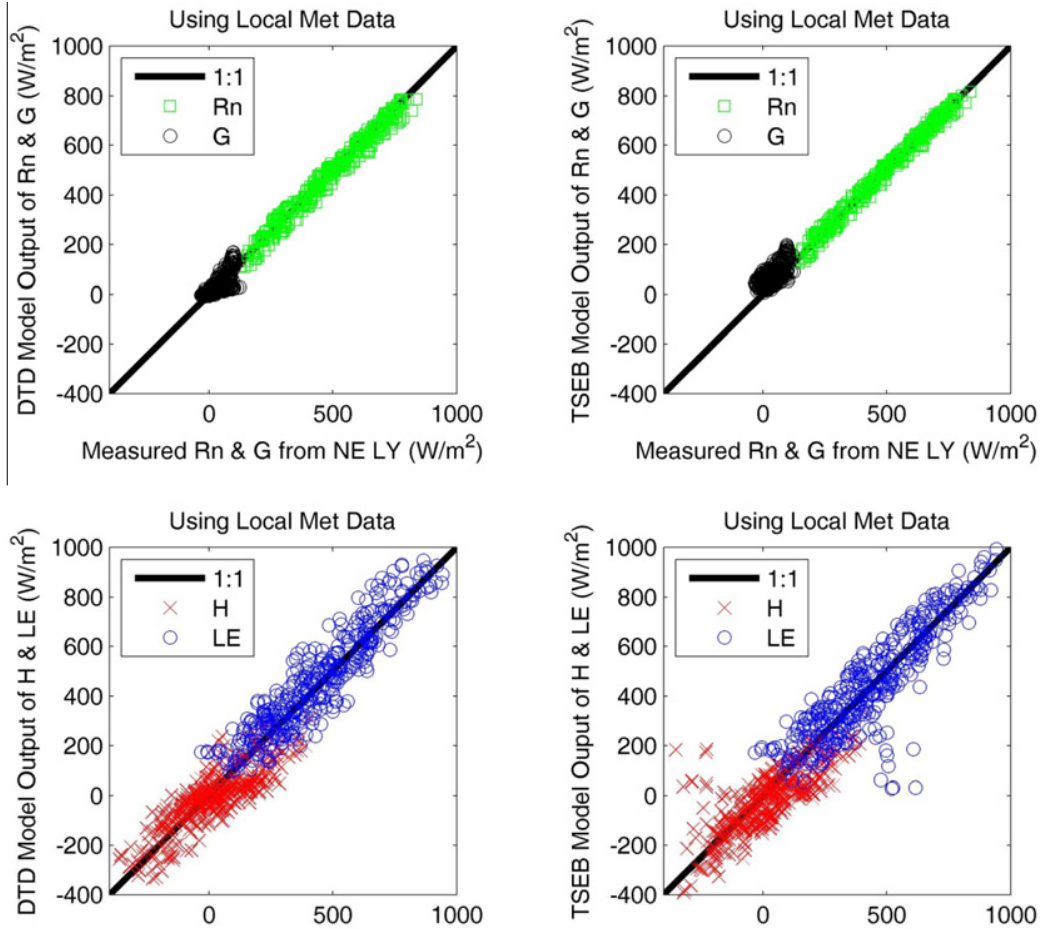

Measured $H$ (residual) \& LE from NE LY $\left(W / \mathrm{m}^{2}\right)$

Measured $H$ (residual) \& LE from NE LY $\left(\mathrm{W} / \mathrm{m}^{2}\right)$

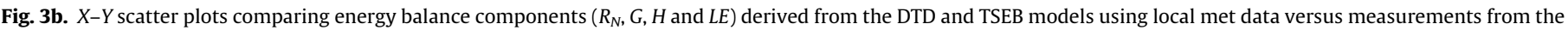
NE LY system where LST was measured. The 1:1 line represents perfect agreement.
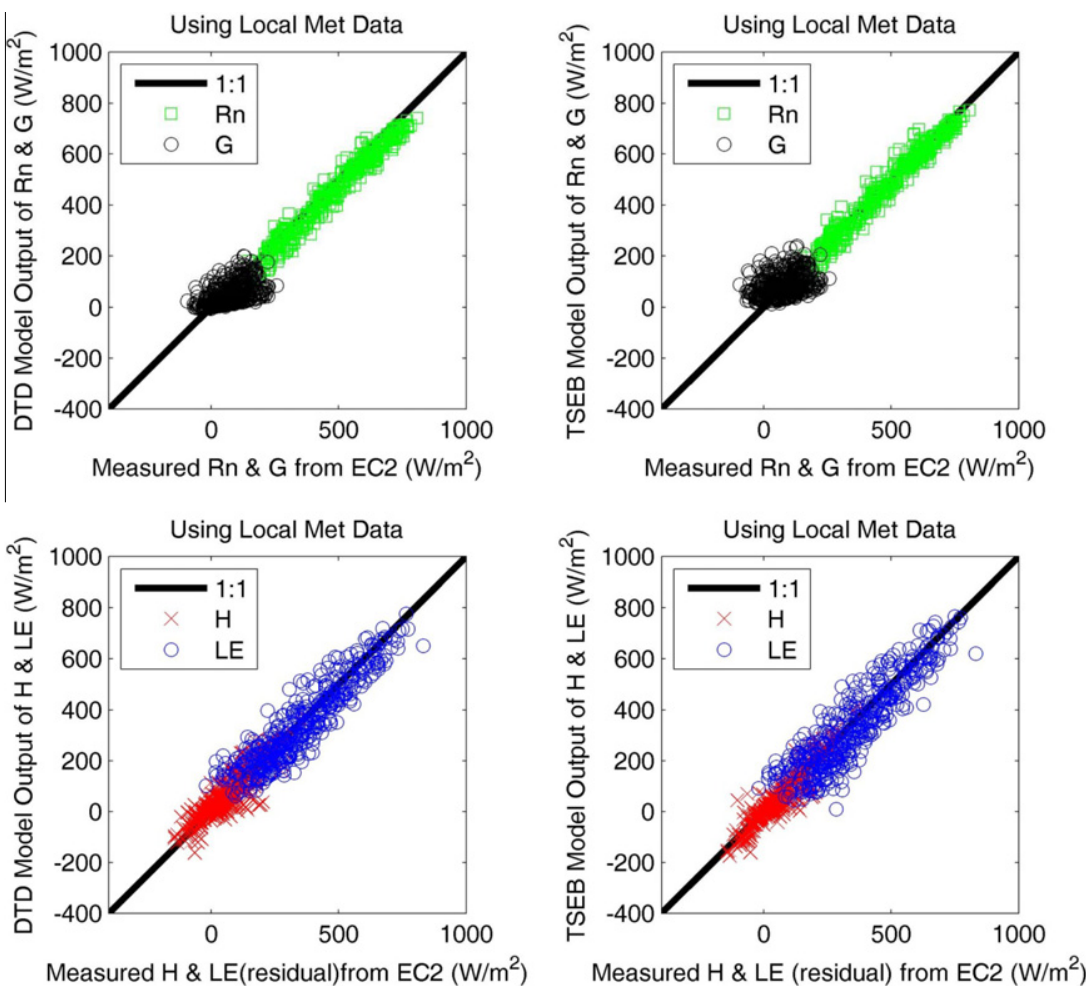

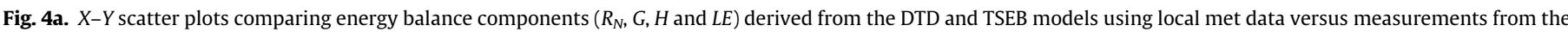
EC2 system deployed in the SE field where LST was measured. The 1:1 line represents perfect agreement.

increase in model-measurement differences using the TSEB with the remote met inputs. In Table 2 , the percentage increase in MAD in model fluxes using the remote met inputs are listed, aver- aged over the four flux sites. For the TSEB model, there is a significant increase in MAD for $H(53 \%)$ and $L E(22 \%)$ when using remote inputs, while for the DTD model fluxes, there is a modest increase 

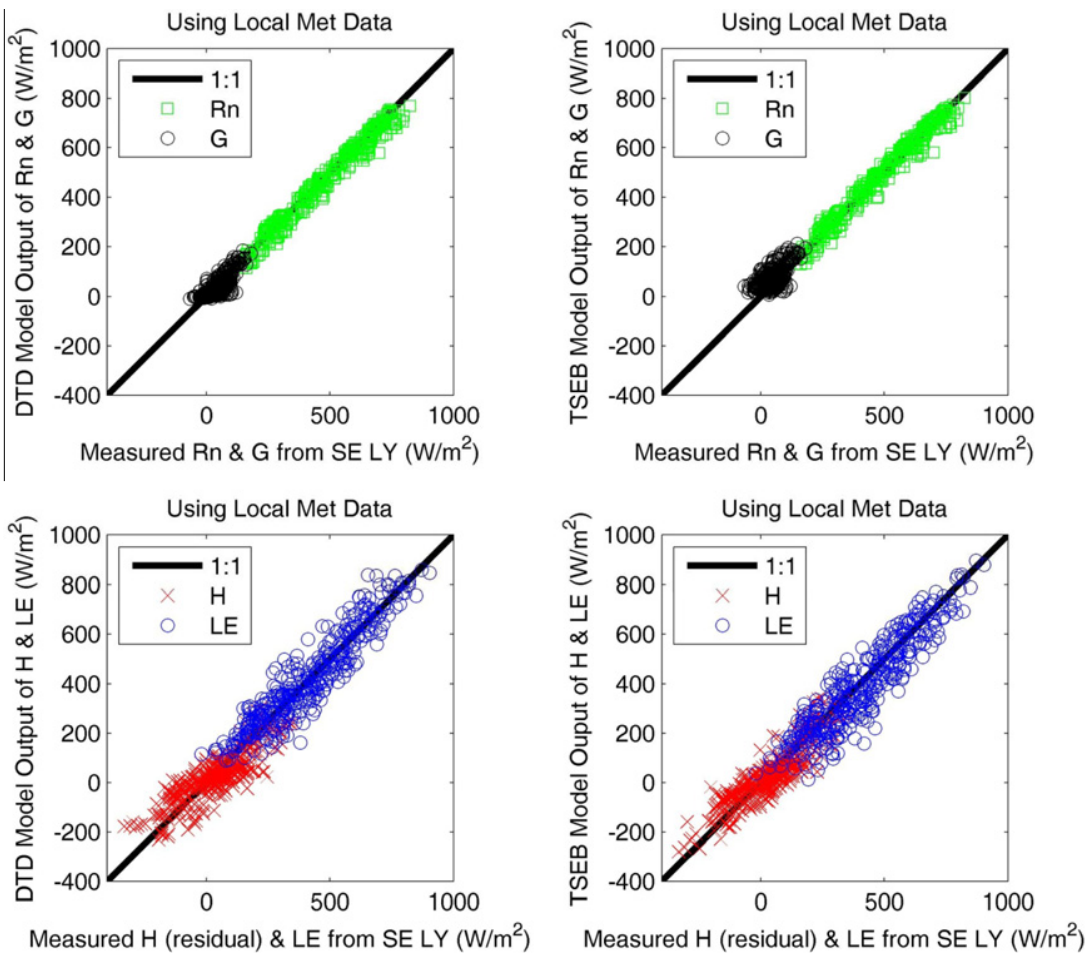

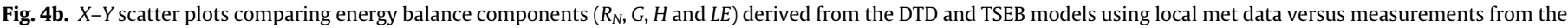
SE LY system where LST was measured. The 1:1 line represents perfect agreement.

in MAD for $H(24 \%)$ and only $9 \%$ for $L E$. The effects of using the remote met data with DTD and TSEB model output on H and LE in comparison to the flux measurements are also illustrated in Figs. 5 and 6 for the four sites. These figures illustrate an increase in both the scatter and bias using the TSEB with the remote versus local met data, while the DTD model produces slightly greater scatter without a significant change in MBD values (see Table 1). As found in other studies (e.g., [11]), the DTD approach reduces errors in using non-local met inputs (primarily air temperature) and biases in LST observations due to sensor calibration and other effects.

In terms of estimating hourly LE/ET, both the TSEB and DTD models yield MAPD values on the order of $15 \%$ when using local met data. Using remote met data, the MAPD increases for the TSEB model to $\sim 20 \%$ on average while it remains $\sim 15 \%$ for the DTD. When summing the modeled and measured $L E$ over the daytime period, the MAPD values are consistently smaller in magnitude. Application of TSEB and DTD with local met data yielded MAPD values of less than 5\% for NE LY and SE LY sites while MAPD from the EC sites tended to be slightly greater on the order of 5 to $10 \%$. Averaging all EC and LY sites yielded a MAPD value on the order of $\sim 6 \%$. Using remote met data, the MAPD increases using the TSEB model to $\sim 10 \%$, on average, while remaining $\sim 5 \%$ when applying the DTD approach. In terms of daytime total ET in mm of water, MAD values using local met data with TSEB and DTD models were $\sim 0.5 \mathrm{~mm}$, on average, while the use of remote met data mainly affected the performance of the TSEB model, with the MAD values reaching $\sim 0.8 \mathrm{~mm}$, but only a slight increase in the average MAD for all the sites of $\sim 0.6 \mathrm{~mm}$.

\subsection{TSEB and DTD model performance using non-local LST and LAI inputs}

Although both EC8 and EC9 were in close proximity to NE LY and SE LY (within $\sim 25 \mathrm{~m}$ ), the vegetation conditions within their source area footprints were measurably different from those inside the $\sim 9 \mathrm{~m}^{2}$ surface area of the lysimeters (cf. Fig. 1). Alfieri et al. [30] quantified these differences using a combination of ground observations and high resolution aircraft imagery and determined the LAI at NE LY for the period of accelerated growth DOY 190-210 was from 20 to 75\% higher than within the time-averaged EC8 flux footprint, while at SE LY, LAI was 5 to $25 \%$ higher than in the EC9 footprint. However, LST, $R_{N}$ and $G$ time series were only acquired at the lysimeter sites.

Fig. 7 demonstrates errors resulting in modeling fluxes from EC8 and EC9 using LAI, LST, $R_{N}$ and $G$ from the nearby lysimeter sites. Resulting biases are generally larger than for the EC1, EC2, SE LY and NE LY simulations (see Table 3). This bias is greatest for the extreme (high and low) values of $H$ and $L E$ values and is more apparent for EC8 than EC9. This is not surprising since the differences in vegetation cover (LAI) is much greater between EC8 and NE LY than between EC9 and SE LY (see Fig. 1).

To provide a perspective as to the significance of the differences between modeled and measured fluxes in relation to the uncertainty in the in-situ flux measurements, a brief summary of the intercomparison of fluxes from the EC and LY systems for NE and SE fields by Alfieri et al. [30] is provided. In that study, Alfieri et al. noted that $L E$ from LY during the daytime consistently exceeded EC from 50 to nearly $150 \mathrm{~W} \mathrm{~m}^{-2}$, while $H$ from LY solved by residual typically yielded values greater than EC in magnitude. This was most notable under strongly advective conditions in the afternoon where $H<0$, and as a result $H(\mathrm{EC})-H(\mathrm{LY})$ ranged from 50 to $100 \mathrm{~W} \mathrm{~m}^{-2}$ on average. In addition, differences in estimates of $G$ from EC and LY sites ranged between 50 and $100 \mathrm{~W} \mathrm{~m}^{-2}$ on average during the mid morning period when $G$ is maximum. These results indicate that differences between modeled and measured surface fluxes are due in part to biases in flux observations among the measurement systems, that relate to differences in vegetation cover conditions (LAI) affecting the different measurement systems, as illustrated in Fig. 1. This also helps to explain why a greater bias was observed between modeled and measured $H$ 


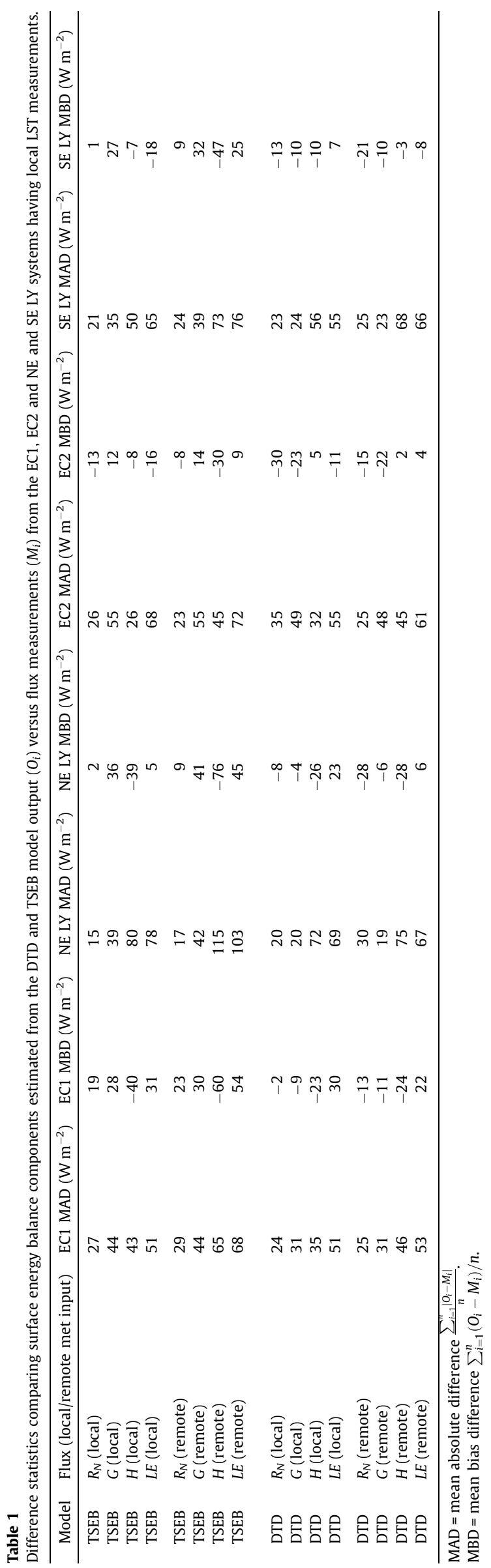

Table 2

Percentage increase in MAD using remote versus local met data.

\begin{tabular}{lll}
\hline Flux & $\begin{array}{l}\text { Change in MAD for the DTD } \\
\text { model (\%) }\end{array}$ & $\begin{array}{l}\text { Change in MAD for the TSEB } \\
\text { model }(\%)\end{array}$ \\
\hline$R_{N}$ & 23 & 12 \\
$G$ & 3 & 5 \\
$H$ & 24 & 53 \\
$L E$ & 9 & 22 \\
\hline
\end{tabular}

and $L E$ especially for EC8 since LST observations came from the NE LY which had significantly greater plant cover (LAI; see Fig. 1).

\subsection{Sensitivity of TSEB and DTD model performance to key input data}

There have been several sensitivity studies investigating a fairly extensive set of input variables affecting the TSEB approach [27,36-38]. All of these sensitivity studies find that the TSEB model performance is mainly affected by the uncertainty in surface-air temperature differences, either due to errors in determining the surface radiometric temperature, use of non-local air temperature observation or a combination of both. This was the main reason for developing the DTD scheme. Although, significant errors in fractional vegetation cover/LAI and wind speed can also cause considerable variation TSEB model output, it is the errors in the surface-air temperature difference that often leads to the greatest impact on TSEB model performance. This has led to recent attempts to develop a practical method for estimating the main spatial patterns in the wind speed and air temperature using results from large eddy simulations coupled to remotely sensed LST, LAI and land cover/land use [39].

To conduct another even more extensive sensitivity analysis is beyond the scope of the current paper. Instead, a "worst case scenario" was constructed for such a strongly advective environment to evaluate the impact on both TSEB and DTD model output. A day towards the end of the IOP (DOY 215) was selected having significant canopy cover, high radiation, moderate winds and strong advection (sensible heat flux directed towards the surface) in the early afternoon. The imposed errors in the key inputs were a $+1 \mathrm{~K}$ and $\mathrm{a}+3 \mathrm{~K}$ increase in $T_{A, 0}$ and $T_{A, i}$, respectively, an underestimate of $T_{R, i}(\phi)$ of $-2 \mathrm{~K}$ for the afternoon observation based on a recent study by Tang et al. [40] and an increase by a factor of 1.5 in wind speed, $u$, namely $1.5 \times u_{0}$ and $u_{i}$. This scenario is based on the fact that the non-local meteorological observations are most likely to come from a nearby airport (such as the remote met data used in the current study) which tends to have the weather station located in an open non-irrigated area near an airport tarmac, hence a smooth dry surface. It is also one of the weather station location types shown to have significant effects on the TSEB model output applied to an image/modeling domain [39]. The flux observations from EC1 and the reference and re-computed fluxes with the errors in $T_{R}(\phi), T_{A}$, and $u$ described above are listed in Table 4 . The computed flux output for the worst case scenario indicates that both DTD and TSEB models are nearly equally affected by these errors. This is because in the case of both $T_{A}$ and $T_{R,}(\phi)$ the bias was not constant between the initial and second observation, which makes the DTD less effective in compensating for such errors. The largest relative error is in $\mathrm{H}$, yielding $\sim 200 \%$ and $400 \%$ deviations from the reference case using the TSEB and DTD model, respectively, while for $L E$, the relative error in TSEB and DTD model output is approximately $30 \%$ and $25 \%$, respectively. It is interesting to note that LE from the lysimeter (NE LY) for this period was $844 \mathrm{~W} \mathrm{~m}^{2}$, indicating that discrepancies in the measurements ( $31 \%)$ can at times be comparable to significant model errors. 

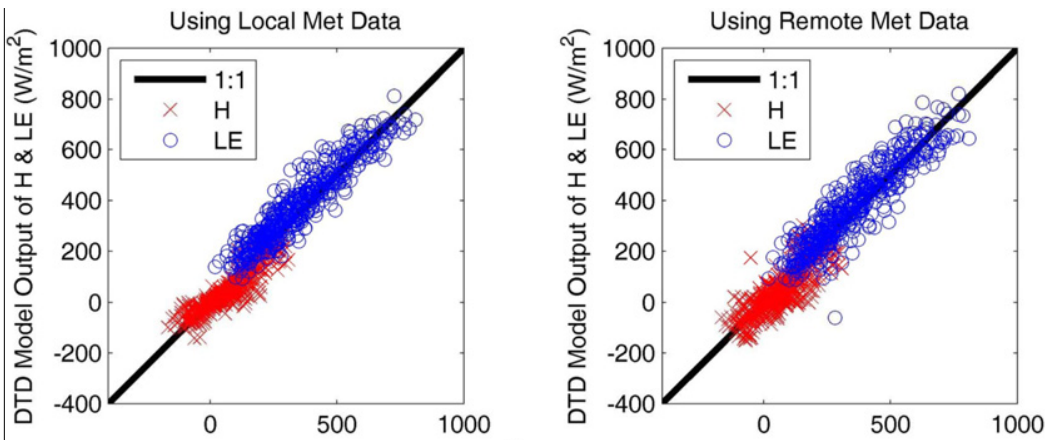

Measured $H$ \& LE (residual) from EC1 $\left(\mathrm{W} / \mathrm{m}^{2}\right)$

Measured H \& LE (residual) from EC1 $\left(\mathrm{W} / \mathrm{m}^{2}\right)$
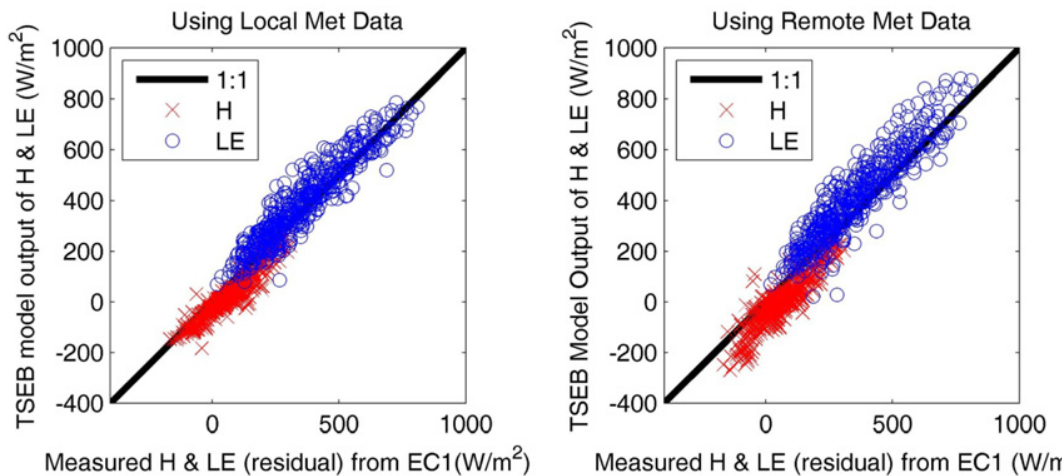

Measured H \& LE (residual) from EC1 $\left(\mathrm{W} / \mathrm{m}^{2}\right)$

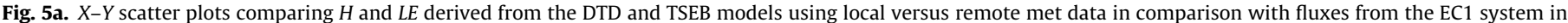
the NE field. The 1:1 line represents perfect agreement.
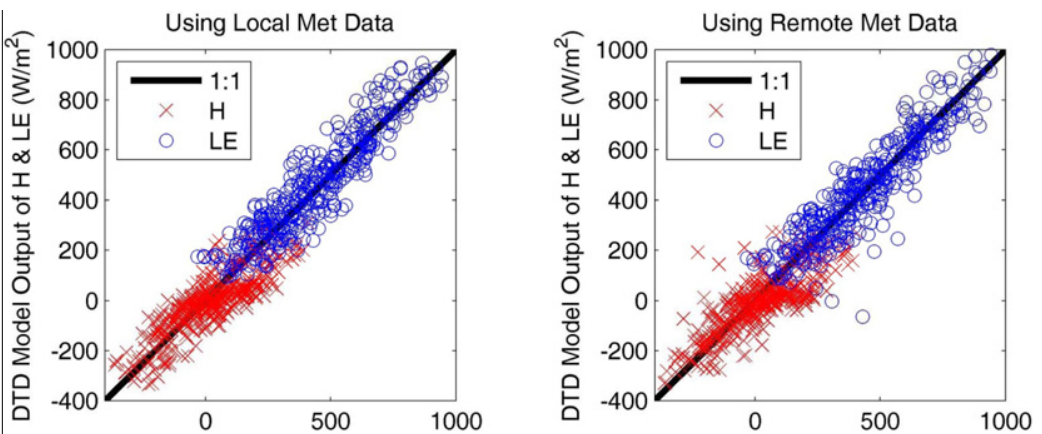

Measured $H$ (residual) \& LE from NE LY $\left(W / m^{2}\right)$

Measured $H$ (residual) \& LE from NE LY $\left(W / m^{2}\right)$
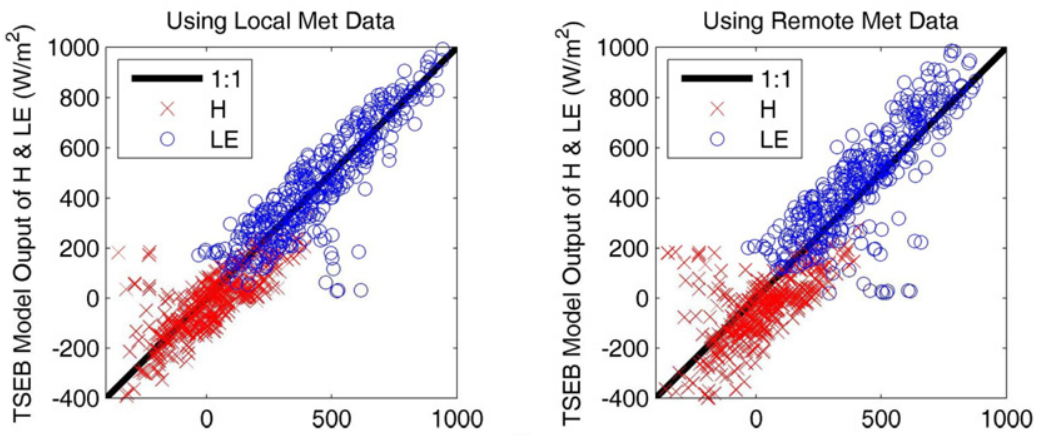

Measured $H$ (residual) \& LE from NE LY $\left(W / m^{2}\right)$

Measured $H$ (residual) \& LE from NE LY $\left(W / \mathrm{m}^{2}\right)$

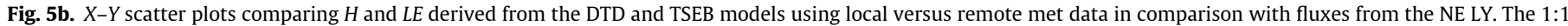
line represents perfect agreement.

\section{Concluding remarks}

The comparison of TSEB and DTD model output of surface energy fluxes with measurements from BEAREX08 suggests that model performance is significantly affected by the representativeness of the measurements and associated key model input variables, namely LST, LAI and meteorological inputs (primarily air temperature, $T_{A}$ ). In such irrigated and strongly advective 

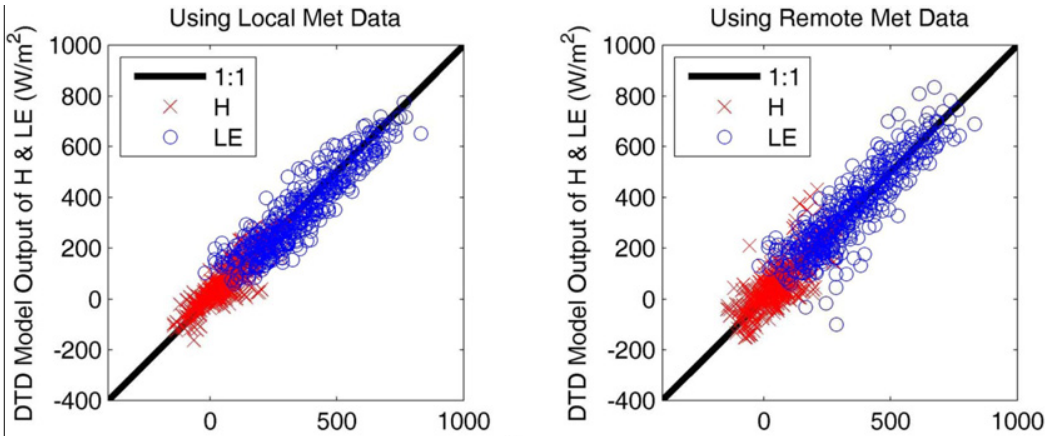

Measured $H$ \& LE (residual) from EC2 $\left(W / m^{2}\right)$

Measured $H$ \& LE (residual) from EC2 $\left(\mathrm{W} / \mathrm{m}^{2}\right)$

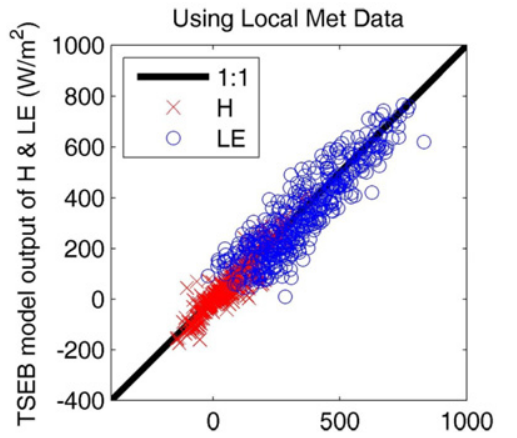

Measured H \& LE (residual) from EC2 $\left(W / \mathrm{m}^{2}\right)$

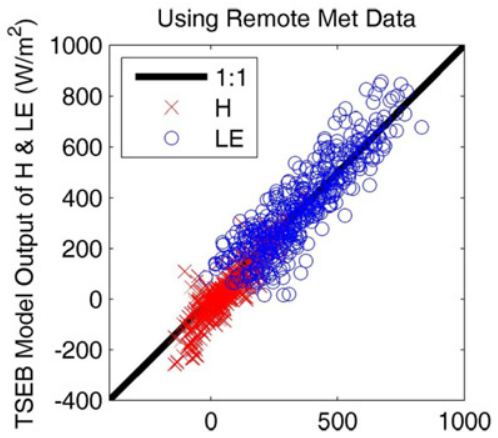

Measured H \& LE (residual) from EC2 $\left(\mathrm{W} / \mathrm{m}^{2}\right)$

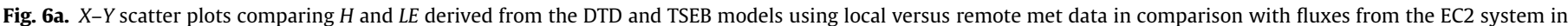
the SE field. The 1:1 line represents perfect agreement.
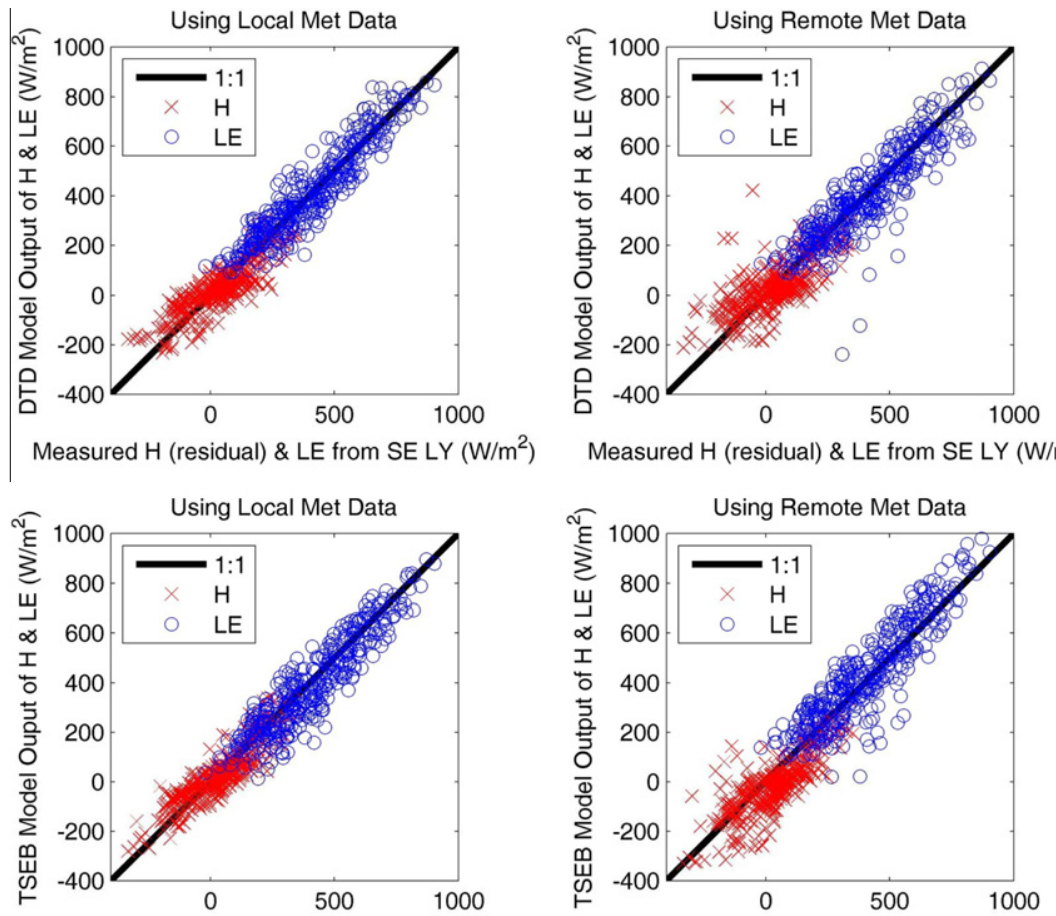

Measured $\mathrm{H}$ (residual) \& LE from SE LY $\left(\mathrm{W} / \mathrm{m}^{2}\right)$

Measured $H$ (residual) \& LE from SE LY $\left(W / \mathrm{m}^{2}\right)$

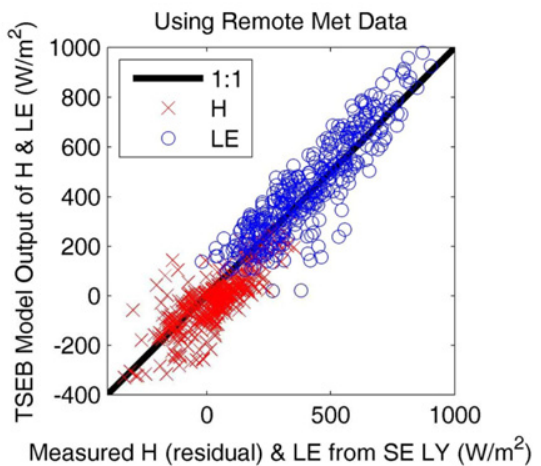

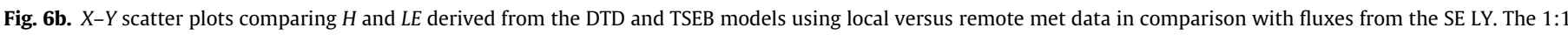
line represents perfect agreement.

environments, variability in these inputs are likely to be more extreme and have a greater impact on modeled and measured fluxes since often $L E$ significantly exceeds the available energy.
Consequently, LAI, LST and $T_{A}$ measurements need to reflect conditions within and above the source area of the measurement system and are critical factors for model evaluation/testing. 

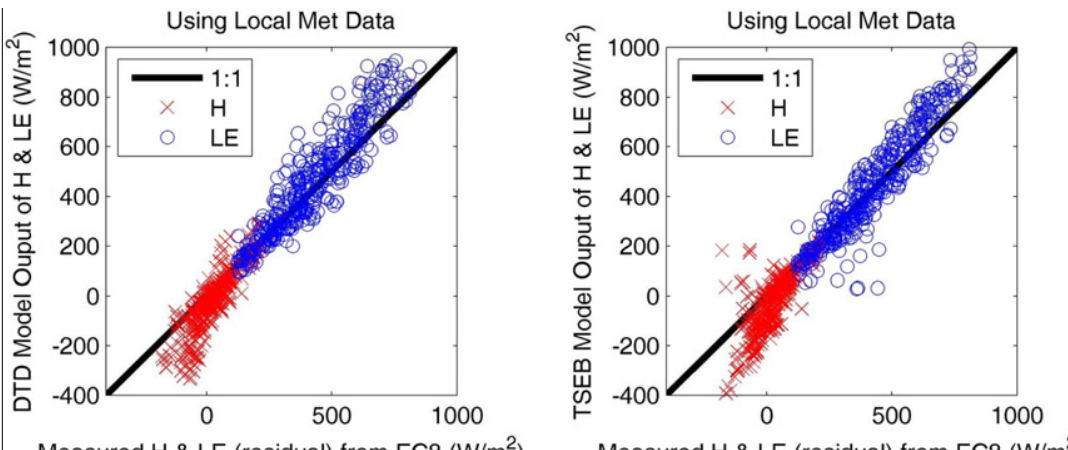

Measured H \& LE (residual) from EC8 $\left(\mathrm{W} / \mathrm{m}^{2}\right)$

Measured $\mathrm{H}$ \& LE (residual) from EC8 $\left(\mathrm{W} / \mathrm{m}^{2}\right)$
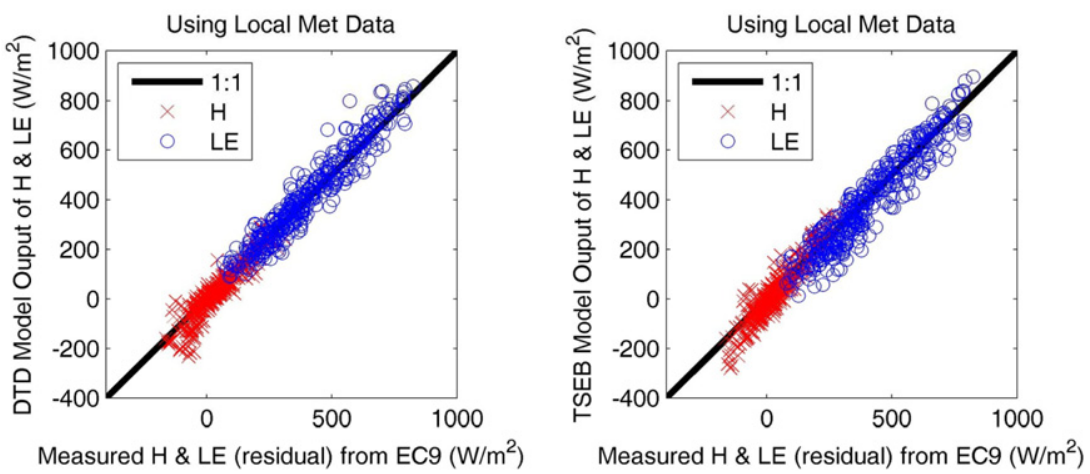

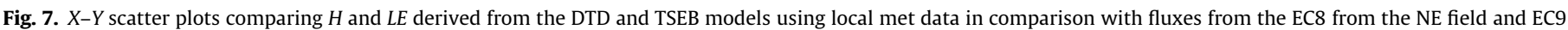
from the SE field. Note that LST is measured at NE LY and SE LY. The 1:1 line represents perfect agreement.

Table 3

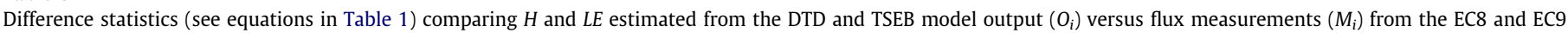
systems.

\begin{tabular}{|c|c|c|c|c|c|}
\hline Model & Flux (local/remote met input) & EC8 MAD $\left(\mathrm{W} \mathrm{m}^{-2}\right)$ & $\mathrm{EC} 8 \mathrm{MBD}\left(\mathrm{W} \mathrm{m}^{-2}\right)$ & EC9 MAD $\left(\mathrm{W} \mathrm{m}^{-2}\right)$ & $\mathrm{EC9} \operatorname{MBD}\left(\mathrm{W} \mathrm{m}^{-2}\right)$ \\
\hline TSEB & $H$ (local) & 67 & -53 & 33 & -10 \\
\hline TSEB & $L E$ (local) & 65 & 19 & 52 & -16 \\
\hline DTD & $H$ (local) & 51 & -40 & 28 & -13 \\
\hline DTD & $L E$ (local) & 69 & 36 & 41 & 10 \\
\hline
\end{tabular}

Table 4

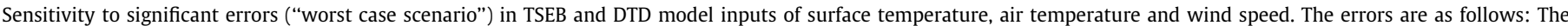

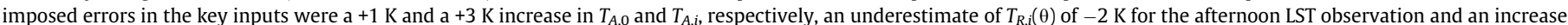
by a factor of 1.5 in wind speed, $u$, namely $1.5 u_{0}$ and $1.5 u_{i}$.

\begin{tabular}{|c|c|c|c|c|c|c|c|c|c|c|c|c|}
\hline Case & $\begin{array}{l}R_{N} \mathrm{EC} 1 \\
\left(\mathrm{~W} \mathrm{~m}^{-2}\right)\end{array}$ & $\begin{array}{l}\text { G EC1 } \\
\left(\mathrm{W} \mathrm{m}^{-2}\right)\end{array}$ & $\begin{array}{l}H \text { EC1 } \\
\left(\mathrm{W} \mathrm{m}^{-2}\right)\end{array}$ & $\begin{array}{l}L E \text { EC1 } \\
\left(\mathrm{W} \mathrm{m}^{-2}\right)\end{array}$ & $\begin{array}{l}R_{N} \text { TSEB } \\
\left(\mathrm{W} \mathrm{m}^{-2}\right)\end{array}$ & $\begin{array}{l}\text { G TSEB } \\
\left(\mathrm{W} \mathrm{m}^{-2}\right)\end{array}$ & $\begin{array}{l}H \text { TSEB } \\
\left(\mathrm{W} \mathrm{m}^{-2}\right)\end{array}$ & $\begin{array}{l}\text { LE TSEB } \\
\left(\mathrm{W} \mathrm{m}^{-2}\right)\end{array}$ & $\begin{array}{l}R_{N} \text { DTD } \\
\left(\mathrm{W} \mathrm{m}^{-2}\right)\end{array}$ & $\begin{array}{l}\text { G DTD } \\
\left(\mathrm{W} \mathrm{m}^{-2}\right)\end{array}$ & $\begin{array}{l}H \text { DTD } \\
\left(\mathrm{W} \mathrm{m}^{-2}\right)\end{array}$ & $\begin{array}{l}\text { LE DTD } \\
\left(\mathrm{W} \mathrm{m}^{-2}\right)\end{array}$ \\
\hline Reference & 720 & 78 & -55 & 640 & 724 & 88 & -91 & 726 & 709 & 40 & -40 & 709 \\
\hline $\begin{array}{l}\text { Worst } \\
\text { Case }\end{array}$ & 720 & 78 & -55 & 640 & 748 & 105 & -288 & 931 & 736 & 41 & -200 & 894 \\
\hline
\end{tabular}

For BEAREX08, spatial variability in vegetation cover and resulting impact on LST over relatively short distances in irrigated cotton fields had a significant effect on model-measurement performance, especially with the TSEB model. This was exacerbated when using remote meteorological data. For the DTD model, a similar result was found using remote LAI and LST, although use of remote met data had a minor effect on performance in estimating the fluxes. In addition, the DTD model estimates compared to the TSEB showed less bias in $H$ and $L E$ estimates at the extremes when remote LAI and LST were used. The model inputs of LST and LAI that reflect the nominal $9 \mathrm{~m}^{2}$ surface area of the NE and SE lysimeters yielded good agreement with hourly $L E$ measurements resulting in MAPD values between $15 \%$ and $20 \%$ using local and remote met data (see Table 2).
When the hourly $L E$ estimates are summed over the daytime period, the MAPD values using NE LY and SE LY are less than 5\%. This indicates that the DTD and TSEB modeling schemes can yield reliable $L E$ fluxes in this environment as long as the key boundary conditions, LAI and LST, reflect the plant cover/moisture conditions of the source area contributing to the flux. Furthermore, given that the performance of the DTD modeling approach was not significantly affected by the use of remote met data in this advective environment, this might be a simple yet viable technique for robust ET estimates at remote locations where local met observations are unavailable. On the other hand, when the bias in surface and/or air temperature values differ significantly between the two times, the DTD model is shown to have minimal advantage over the TSEB approach. 
Future work will use as input to the TSEB modeling scheme the high resolution LAI and LST derived from the aircraft imagery and averaged over the source-area/flux footprint estimated for the EC tower measurements to determine if this results in an improvement in the model-measurement comparison at the EC tower sites. This will also involve developing a more complex set of corrections to the EC flux measurements based on the results from Alfieri et al. (this issue) for attaining energy balance closure and adjusting for advection of turbulent fluxes. Plans are also to use other sources of remote met inputs to test the sensitivity of the DTD and TSEB model output and to apply these approaches with satellite observations over this region to compare with other more complex LST-based approaches providing regional ET [35]. Finally, based on the preliminary findings of Colaizzi et al. [31] indicating that the partitioning between soil and canopy LE by the TSEB scheme may be unreliable for irrigated row crops in such an advective environment, a more thorough study of the flux partitioning will be performed for both the DTD and TSEB schemes.

\section{Acknowledgements}

This project would not have been possible without the cooperation and assistance of the scientists and staff at the USDA, ARS, Conservation and Production Laboratory, Soil and Water Management Research Unit, Bushland, Texas.

The US Department of Agriculture (USDA) prohibits discrimination in all its programs and activities on the basis of race, color, national origin, age, disability, and where applicable, sex, marital status, familial status, parental status, religion, sexual orientation, genetic information, political beliefs, reprisal, or because all or part of an individual's income is derived from any public assistance program. (Not all prohibited bases apply to all programs.) Persons with disabilities who require alternative means for communication of program information (Braille, large print, audiotape, etc.) should contact USDA's TARGET Center at (202) 720-2600 (voice and TDD). To file a complaint of discrimination, write to USDA, Director, Office of Civil Rights, 1400 Independence Avenue, S.W., Washington, D.C. 20250-9410, or call (800) 795-3272 (voice) or (202) 720-6382 (TDD). USDA is an equal opportunity provider and employer.

\section{References}

[1] Norman JM, Kustas WP, Humes KS. A two-source approach for estimating soil and vegetation energy fluxes from observations of directional radiometric surface temperature. Agric Forest Meteorol 1995;77:263-93.

[2] Evett SR, Kustas WP, Gowda PH, Anderson MC, Prueger JH, Howell TA. Overview of the Bushland Evapotranspiration and Agricultural Remote sensing EXperiment 2008 (BEAREX08): A field experiment evaluating methods for quantifying ET at multiple scales. Adv Water Resour 2012;50:4-19.

[3] Kustas WP, Anderson MC. Advances in thermal infrared remote sensing for land surface modeling. Agric Forest Meteorol 2009;149:2071-81.

[4] Anderson MC, Norman JM, Kustas WP, Houborg R, Starks PJ, Agam N. A thermal-based remote sensing technique for routine mapping of land-surface carbon, water and energy fluxes from field to regional scales. Remote Sens Environ 2008;112:4227-41.

[5] Bhattacharya BK, Mallick K, Nigam R, Dakore K, Shekh AM. Efficiency based wheat yield prediction in semi-arid climate using surface energy budgeting with satellite observations. Agric Forest Meteorol 2011;151:1394-408.

[6] O'Shaughnessy SA, Evett SR, Colaizzi PD, Howell TA. Using radiation thermography and thermometry to evaluate crop stress in soybean and cotton. Agric Water Manage 2011;98:1523-35.

[7] Kalma JD, McVicar TR, McCabe MF. Estimating land surface evaporation: A review of methods using remotely sensed surface temperature data. Survey Geophys; 2008. DOI 10.1007/s10712-008-9037-z.

[8] Norman JM, Becker F. Terminology in thermal infrared remote sensing of natural surfaces. Remote Sens Rev 1995;12:159-73.

[9] Bertoldi G, Albertson JD, Kustas WP, Li F, Anderson MC. On the opposing roles of air temperature and wind speed variability in flux estimation from remotely sensed land surface states. Water Resour Res 2007;43:W10433. http:// dx.doi.org/10.1029/2007WR005911.
[10] Anderson MC, Allen RG, Morse A, Kustas WP. Use of Landsat thermal imagery in monitoring evapotranspiration and managing water resources. Remote Sens Environ 2011.

[11] Norman JM, Kustas WP, Prueger JH, Diak GR. Surface flux estimation using radiometric temperature: a dual temperature difference method to minimize measurement error. Water Resour Res 2000;36:2263-74.

[12] Kustas WP, Diak GR, Norman JM. Time difference methods for monitoring regional scale heat fluxes with remote sensing. Land Surf Hydrol Meteorol Clim Obser Model 2001;3:15-29.

[13] Kustas WP, Anderson MC, Norman JM, Li F. Utility of radiometric-aerodynamic temperature relations for heat flux estimation. Bound-Layer Meteor 2007;122:167-87.

[14] Kustas WP, Norman JM. Evaluation of soil and vegetation heat flux predictions using a simple two-source model with radiometric temperatures for partial canopy cover. Agric Forest Meteorol 1999;94:13-29.

[15] Kustas WP, Norman JM. Reply to comments about the basic equations of dualsource vegetation-atmosphere transfer models. Agric Forest Meteorol 1999;94:275-8.

[16] Kustas WP, Norman JM. Evaluating the effects of subpixel heterogeneity on pixel average fluxes. Remote Sens Environ 2000;74:327-42.

[17] Kustas WP, Norman JM. A two-source energy balance approach using directional radiometric temperature observations for sparse canopy covered surfaces. Agronomy J 2000;92:847-54.

[18] Anderson MC, Norman JM, Kustas WP, Li F, Prueger JH, Mecikalski JM. Effects of vegetation clumping on two-source model estimates of surface energy fluxes from an agricultural landscape during SMACEX. J Hydrometeorol 2005;6:892909.

[19] Colaizzi PD, O'Shaughnessy SA, Gowda PH, Evett SR, Howell TA, Kustas WP, et al. Radiometer footprint model to estimate sunlit and shaded components for row crops. Agron J 2010;102:942-55.

[20] Priestley CHB, Taylor RJ. On the assessment of surface heat flux and evaporation using large-scale parameters. Mon Weather Rev 1972;100:81-92.

[21] Tanner CB, Jury WA. Estimating evaporation and transpiration from a row crop during incomplete cover. Agron J 1976;68:239-42.

[22] Castellvi F, Stockle CO, Perez PJ, Ibanez M. Comparison of methods for applying the Priestley-Taylor equation at a regional scale. Hydrol Process 2001;15:1609-20.

[23] Agam N, Kustas WP, Anderson MC, Norman JM, Colaizzi PD, Howell TA, et al. Application of the Priestley-Taylor approach in a two-source energy balance model. J Hydrometeorol 2010;11:185-98.

[24] Santanello JA, Friedl MA. Diurnal variation in soil heat flux and net radiation. J Appl Meteorol 2003;42:851-62.

[25] Kustas WP, Daughtry CST. Estimation of the soil heat flux/net radiation ratio from spectral data. Agric Forest Meteorol 1990;49:205-23.

[26] Li F, Kustas WP, Prueger JH, Neale CMU, Jackson TJ. Utility of remote sensing based two-source energy balance model under low and high vegetation cover conditions. J Hydrometeorol 2005;6:878-91.

[27] Anderson MC, Norman JM, Diak GR, Kustas WP, Mecikalski JR. A two-source time-integrated model for estimating surface fluxes using thermal infrared remote sensing. Remote Sens Environ 1997;60:195-216.

[28] Marek TH, Schneider AD, Howell TA, Ebeling LL. Design and construction of large weighing monolithic lysimeters. Trans ASAE 1988;31:477-84.

[29] Evett SR, Schwartz RC, Howell TA, Baumhardt RL, Copeland KS. Can weighing lysimeter ET represent surrounding field ET well enough to test flux station measurements of daily and sub-daily ET? Adv Water Resour 2012;50:79-90.

[30] Alfieri JG, Kustas WP, Prueger J, Hipps LE, Evett SR, Basara JB, et al. On the discrepancy between eddy covariance and lysimetry-based surface flux measurements under strongly advective conditions. Adv Water Resour 2012;50:62-78.

[31] Colaizzi PD, Kustas WP, Anderson MC, Gowda PH, O’Shaughnessy SA, Howell $\mathrm{TA}$, et al. Two-source model estimates of evapotranspiration using component and composite surface temperatures. Adv Water Resour 2012;50:134-51.

[32] Prueger JH, Hatfield JL, Kustas WP, Hipps LE, MacPherson JI, Parkin TB. Tower and aircraft eddy covariance measurements of water vapor, energy and carbon dioxide fluxes during SMACEX. J Hydrometeor 2005;6:954-60.

[33] Cosh MH, Evett SR, McKee LG. Surface soil water content spatial organization within irrigated and non-irrigated agricultural fields. Adv Water Resour 2012;50:55-61.

[34] Willmott CJ, Matsuura K. Advantages of the mean absolute error (MAE) over the root mean square error (RMSE) in assessing average model performance. Clim Res 2005;30:79-82.

[35] Anderson MC, Kustas WP, Alfieri JG, Gao F, Hain CR, Evett SR, et al. Mapping daily evapotranspiration at landsat spatial scales during the BEAREX'08 field campaign. Adv Water Resour 2012;50:162-77.

[36] Zhan X, Kustas WP, Humes KS. An intercomparison study on models of sensible heat flux over partial canopy surfaces with remotely sensed surface temperature. Remote Sens Environ 1996;58:242-56.

[37] Kustas WP, Norman JM. A two-source approach for estimating turbulent fluxes using multiple angle thermal infrared observations. Water Resour Res 1997;33:1495-1508.

[38] Timmermans, WJ, Kustas WP, Anderson MC, French AN. An intercomparison of the surface energy balance algorithm for land (SEBAL) and the two-source 
energy balance (TSEB) modeling schemes. Remote Sens Environ 2007;108:369-84

[39] Bertoldi G, Kustas WP, Albertson AD. Estimating spatial variability in atmospheric properties over remotely sensed land surface conditions. J Appl Meteorol Climatol 2008;47:2147-65.
[40] Tang R, Li Z-L, Jia Y, Li C, Sun X, Kustas WP, et al. An intercomparison of three remote sensing-based energy balance models using Large Aperture Scintillometer measurenments overa wheat-corn production region. Remote Sens Environ 2011;115:3187-3202. 